\title{
Resenha
}

KISHIMOTO, Alexandre. Cinema japonês na Liberdade. São Paulo, Estação Liberdade, 2013, 304pp.

\section{Os Públicos de cinema na Liberdade}

\author{
Bianca Salles Pires \\ Universidade Federal do Rio de Janeiro, Rio de Janeiro, RJ, Brasil \\ bianca.s.pires@gmail.com
}

Cinema japonês na Liberdade, é um livro que resulta da pesquisa realizada pelo antropólogo Alexandre Kishimoto, junto aos imigrantes japoneses e seus descendentes na cidade de Sáo Paulo. Tendo como foco as relaçóes sociais, os costumes e as ritualidades que podem ser explicitadas a partir das lembranças e memórias acerca das interações que ocorriam nas salas de cinemas, voltadas exclusivamente para a exibição de filmes japoneses. A investigação nos convida a observar "o caráter polimorfo adquiridos pelos fluxos culturais através das distâncias" (:272), apresentando as inúmeras variaçôes existentes entre os japoneses e os nikkeis no contexto da pesquisa. O conceito de "identidade japonesa" é tratado aqui não para reiterar a existência de uma "colônia japonesa" no bairro da Liberdade, mas sim de como o "ser japonês", habitando em São Paulo, foi vivenciado de maneiras plurais por esses imigrantes e seus descendentes. As salas de cinemas e seus filmes são abordados a partir dos relatos das experiências vividas nos espaços, o que possibilita um novo olhar acerca das relaçóes que esses imigrantes, os nikkeis e os não nikkeis, frequentadores dos cinemas, estabeleceram com a cidade e de que maneira suas relaçóes com o Estado nacional variaram ao longo do século XX. Ao dar ênfase aos aspectos rituais presentes nas idas às salas de exibição por esses últimos, o autor apresenta a importância destes eventos como criadores de identidades, etnias, sexualidades e gêneros. 
O trabalho de Alexandre Kishimoto sugere uma aproximação a estes "estrangeiros permanentes" dando foco aos seus momentos de lazer, o que torna a sua análise original. Em pouco mais de 300 páginas de leitura fluida, o autor de Cinema japonês na Liberdade originariamente apresentado como uma dissertação de mestrado em Antropologia Social pela Fflch/USP - oferece ao leitor os resultados da investigação das representaçóes destes antigos frequentadores, composta por suas memórias, lembranças e interpretaçóes dos filmes e das idas às salas de cinema. Quando se tratava dos nikkeis, o pesquisador procurou agregar perguntas que acrescentassem às vivências nos cinemas os "procedimentos de história de vida" (:22), que possibilitassem ao entrevistado compor e combinar esse passado de maneira que achasse mais apropriada.

Neste sentido, o livro não pretende dar conta da historiografia das salas de cinema e de seus públicos, mas sim apresentar parte da diversidade de experiências dos frequentadores destes espaços no bairro da Liberdade. Tal alternativa aproxima a investigação dos estudos que levam em conta a relação das salas de cinema com seus públicos, a partir das sociabilidades e experiência partilhada nesses ambientes. Kishimoto desloca a observação da obra de arte para a recepção, não entendida como passiva, mas produzindo significados e sentidos sobre os filmes ao relembrarem das interaçóes que ocorriam nos ambientes dos cinemas. As fotografias das antigas salas, dos públicos, dos momentos de exibiçôes nas ruas e nos diferentes cinemas, dos cartazes de lançamentos dos filmes, de cenas dos filmes, reportagens e premières com os atores e diretores, mais que ilustrativas, ajudam a compor em imagens a narrativa traçada pelo autor, aproximando o leitor da estética japonesa a que se refere o livro.

Cinema japonês na Liberdade se divide em três partes, compostas por seçóes que ajudam a construir a argumentação pretendida. Na primeira parte, chamada As salas de cinema da Liberdade, o autor analisa os antecedentes históricos e a implantaçáo das salas de cinema fixas, com programação composta apenas por filmes japoneses. Os relatos apontam a existência de apresentaçóes dos filmes de origem japonesa mesmo antes da abertura oficial dos cinemas. As exibiçóes em caminhôes ambulantes surgiram nos núcleos rurais por volta dos anos 1926 e 1927, nas fazendas de café que tinham trabalhadores imigrantes. Tratava-se de películas mudas, compostas por curtas metragens de ação, documentários e noticiários. As apresentaçôes contavam muitas vezes com a figura do katsuben, espécie de orador e apresentador do filme, que remete diretamente aos benshi e katsuben no Japão, 
conhecidos como "oradores das imagens em movimento". O circuito de exibição ambulante se espalhava ao longo das linhas férreas pelo interior do Estado de Sáo Paulo, circulando os filmes pelas várias regiôes. Esse período anterior à Segunda Guerra Mundial é tratado pelo autor como de expansão da entrada de obras japonesas, que culminou na fundação das distribuidoras Nippaku Shinema-sha e a Nippon Eiga Kogyo na década de 1930, e na fixação do escritório desta primeira na região da Liberdade. Neste período foram promovidas as primeiras exibiçôes dos filmes japoneses nos Cine Teatros e escolas da região.

Contudo, a eclosão da Segunda Guerra Mundial e as restrições impostas pelo governo Vargas, proibiram a importação de películas japonesas, assim como marginalizaram todas as expressōes culturais dos imigrantes. Entre as interdições foram impedidas a circulação de jornais escritos em japonês, o ensino da língua nas escolas e ocorreram perseguiçóes aos comerciantes e moradores que se encontravam estabelecidos na capital. Esse momento é apresentado pelo autor como parte dos dramas sociais, em referência aos escritos de Victor Turner ${ }^{1}$, pelos quais passaram os imigrantes japoneses na cidade de São Paulo. A "ruptura” trazida pela Guerra, com os laços e referências japonesas, só pôde ser reestabelecida a partir da década de 1950, momento quando, não por acaso, se instalaram as primeiras salas de cinema fixas na Liberdade.

A abertura dos cinemas voltados para as películas japonesas, reestabelece a antiga ocupação do bairro. Primeiramente com o Cine Niterói, inaugurado em 1953, que funcionava como um centro cultural, com restaurante, hotel e salão de baile. O livro sugere que a abertura da sala foi fundamental para a formação e consolidação do comércio japonês na região, "para a caracterização da Liberdade como bairro japonês" (Kishimoto, 2013: p. 39). Posteriormente abriram o Cine Tokyo (1954) - Cine Nikkatu (1962), o Cine Nippon (1959) e o Cine Joia (1952/1959), que apresentavam programaçóes plurais, reafirmando a complexidade das vivências e tipos de experiências que eram suscitadas em cada espaço. O Cine Niterói se caracterizava como o cinema luxuoso, aonde as famílias iam reunidas. $\mathrm{O}$ autor chama atenção para o fato de que as lembranças desta sala estão associadas ao luxo do salão, funcionários gentis, outros serviços oferecidos, existindo poucos relatos quanto a qualidade dos filmes, ou mesmo lembranças do que havia sido assistido. No Cine Tokyo, que teve o nome mudado para Cine Nikkatu, passavam os filmes da chamada nouvelle vague japonesa, que atraiam a um público mais jovem. Já no Cine Nippon, eram passados os filmes das produtoras japonesas dos grandes estúdios, que 
promoviam eventos com a presença dos atores. As narrativas dos filmes exibidos no Cine Nippon foram apresentadas de maneiras diferentes pelos entrevistados, o que reforça a argumentação do autor de que a recepçáo manipula os fluxos culturais de maneira ativa, isso é, existem esquemas locais de significação. O Cine Joia, que foi projetado para ser um cinema de bairro por Serrador, passa a ser controlado pela exibidora Toho em 1959, e contava com obras de cineastas de prestígio internacional. $\mathrm{O}$ espaço é lembrado como de infraestrutura ruim, mas exibindo filmes de qualidade.

O autor continua o capítulo apresentando os outros usos dos espaços para além da apreciação das películas. Bailes, festas com presença de atores, paquera nas filas e reunião de famílias compóe o que eram as idas às salas de cinema no bairro da Liberdade, e chamam a atenção para as várias ritualizaçóes que se tornavam presentes em cada um dos espaços. Os significados de ir aos cinemas na companhia dos pais, e a memória da reação destes ao saírem do cinema; a lembrança das primeiras idas às salas de exibição sozinha com os amigos; a importância dada às estreias das películas e aos momentos de espera que antecediam a entrada nas salas de exibição; os filmes melodramáticos, que faziam o público feminino coletivamente chorar; são alguns exemplos apresentados no livro que denotam “as experiências coletivas" provocadas pelas exibições dos filmes japoneses.

As lembranças dos entrevistados associam as salas aos estúdios responsáveis pelos filmes, que suscitavam experiências diferenciadas e atraíam a "tipos de públicos” específicos. Aqui o autor nos convida a perceber "a importância e a dimensão que o ato de ir ao cinema adquiriu na história de vida dessas pessoas" (:84). O cinema e os momentos de lazer são analisados como constituidores de significados para o público, o que incluí a fruição da película assistida, mas também o antes, o durante e o depois do filme. Neste sentido, o livro apresenta aspectos pouco explorados pelos estudos antropológicos acerca da recepção de cinema, demonstrando a estima que estes tiveram no século passado, ao mesmo tempo em que chama a atençáo para uma análise que inclua as ritualidades que estavam presentes antes, durante e depois de assistir filme. Ainda que os relatos apresentem um caráter nostálgico, criando uma oposição entre o passado e o que é vivido atualmente nas salas de cinemas em Sáo Paulo, o tipo de análise nos convida a observar as possibilidades de significaçóes e sentidos que as frequências aos eventos culturais exercem ainda hoje.

$\mathrm{Na}$ segunda parte do livro, Os filmes japoneses em Sáo Paulo, o autor vai apresentando as especificidades dos filmes produzidos no Japão em relação à crescente 
produção estadunidense. Após a Segunda Guerra, e com a Europa devastada pelo conflito, os estúdios de Hollywood passam a produzir e expandir para o mundo suas obras cinematográficas. No Brasil, isso significou a administração de salas de cinema por estúdios de nacionalidade norte-americana e a massificação da entrada de tais filmes. No entanto, as aberturas das salas de cinemas na Liberdade são percebidas pelo autor, e também pelos críticos e cineastas de São Paulo formados nesse período, como espaços de resistências. Esta última tinha um duplo sentido, por um lado significou a retomada e fixação dos japoneses na regiáo da Liberdade, com abertura de lojas, espaços culturais e serviços especializados; por outro significou a possibilidade de assistir películas que tinham outros tipos de narrativas, diferentes questóes estéticas e maneiras distintas de montagens e temporalidades.

As análises dos comentários feitos acerca dos filmes pelos imigrantes demonstraram um sentimento de negação às influências ocidentais nos mesmos. Após a derrota na Segunda Guerra, a cinematografia japonesa passou a ter reconhecimento junto às premiaçóes internacionais, possibilitando uma maior abertura aos filmes no Ocidente. A realidade de São Paulo era atípica nesse cenário mundial, a cidade contava com a maior colônia japonesa fora do Japão, e eram exibidos filmes japoneses dos mais variados tipos. Contudo, ainda que a postura dos imigrantes tenha sido de rejeição aos "diretores ocidentalizados", o livro sugere que os filmes de época, vistos como direcionados para os circuitos de festivais e mercados cinematográficos ocidentais, possibilitaram uma maior abertura para a fruição desses filmes por outros públicos. $\mathrm{O}$ bairro da Liberdade e as suas salas de cinema passaram a ser visitados por outros frequentadores que não os imigrantes e seus descendentes. Esse processo possibilitou uma reintegração da região, dos imigrantes e seus descendentes, à cidade de São Paulo.

Outras obras cinematográficas são citadas ao longo do capítulo, assim como relatos dos imigrantes, descendentes, cineastas e críticos de cinema. Demonstrando a pluralidade de significados atribuídos aos filmes, que variavam segundo a idade, interesse, gênero, gosto estético e posição política dos espectadores. Aqui o quadro construído pelo autor demonstra a pluralidades de vivências experimentadas pelos imigrantes, seus descendentes e os nikkeis nos cinemas. A imagem de um público japonês dá lugar aos púbicos no plural. Ainda que argumente buscando criar características comuns aos frequentadores de cada sala de cinema em relaçáo aos dos outros espaços, uma vez que elas estavam ligadas aos estúdios e passavam um determinado tipo de filme, os relatos demonstram que os indivíduos fluíam entre as 
várias salas disponíveis na cidade. E se demonstravam ter algum tipo de predileção por alguma sala, não deixavam de participar das estreias de filmes badalados em outro cinema caso o "programa” parecesse interessante.

O autor fecha o segundo capítulo com duas perguntas chave: haveria significados mais gerais atribuídos à experiência de frequentar cinemas? Como se relacionam os diferentes grupos de apreciadores do cinema japonês?

Partindo dessas indagaçóes, a terceira parte do livro - O público paulista - costura algumas das análises realizadas durante o livro para a construção da argumentação dos públicos dos cinemas japoneses em Sáo Paulo e da importância que essas salas tiveram para os imigrantes e seus descendentes. Retoma, neste sentido, a ideia de "ruptura" trazida pela Segunda Guerra, quando os costumes e expressôes culturais passaram a ser repreendidos pelo Estado nacional. A falta de informaçóes precisas quanto ao fim da Guerra, pela proibição da circulação de jornais japoneses, e a não aceitação por parte dos imigrantes da derrota na Guerra produziram conflitos internos ao coletivo dos imigrantes, ao mesmo tempo em que provocaram uma reafirmação da identidade japonesa em reação às discriminaçóes sofridas. A fissura dentro da própria comunidade, considerada pelo autor como a "intensificação da crise", era caracterizada por uma divisão entre aqueles considerados kachigumi - vitoristas - "que mantinham a crença na infalibilidade do imperador e na infalibilidade do Japão" (:190), e os makegumi - derrotistas - "que aceitavam a derrota do Japáo e a derrocada de valores como o culto divino ao imperador" (:190).

Para o autor, os cinemas serviram como espaços de "reconciliaçáo", por meio das catarses coletivas e da retomada de sociabilidades entre os imigrantes e os nikkeis, e entre os kachigumi e os makegumi. Ao mesmo tempo, as premiaçôes internacionais simbolizaram uma abertura maior do Ocidente para a cinematografia japonesa. Em São Paulo isso refletiu em uma maior afluência de não nikkeis às salas de cinema na Liberdade e uma reintegração dos imigrantes e descendentes com a sociedade paulista mais ampla. Neste sentido, a abertura do Cine Niterói, e a ocupação do bairro pelo comércio, lazer e letreiros em japonês; a possibilidade de assistirem coletivamente aos filmes que tratavam da Segunda Guerra Mundial, vistos como de efeito catártico; e a presença de visitantes japoneses na cidade de São Paulo, que podiam relatar suas experiências durante a guerra, permitiram que as informaçóes fossem partilhadas e vivenciadas coletivamente. 
O conceito de drama social de Turner (2005) é novamente utilizado pelo autor para caracterizar sua análise da comunidade japonesa na passagem do tempo, e na "ruptura" que significou a Guerra para esses imigrantes e seus descendentes. O desenrolar histórico que culminou numa "intensificação da crise", e teve como "ação reparadora" a retomada das sociabilidades nos espaços dos cinemas e no bairro da Liberdade. $\mathrm{O}$ reencontro com o Japão e a atualização por meio dos filmes se tornaram possíveis a partir dos filmes com continuidade, que recontavam as grandes histórias e faziam referências ao teatro japonês; do áudio em japonês, que acentuava as diferenças entre os sotaques, ao mesmo tempo em que traziam as músicas, e maneiras de se expressar no Japão "atual" para esses imigrantes; a educação sentimental de expressóes próprias do país de origem.

Um último trecho é dedicado à integração da comunidade japonesa à sociedade paulista mais ampla, com a intensificação da frequência de não nikkeis aos cinemas da Liberdade e a exibição de alguns filmes em salas de projeção em outras regióes da cidade. Os críticos e cineastas paulistas são os não nikkeis entrevistados pelo antropólogo, o que expressa um limite da pesquisa. Ao propor uma investigação junto aos antigos públicos, Kishimoto lidou com entrevistados que já ultrapassavam os 60 anos de idade, e diante disso, teve acesso apenas a uma rede mais próxima e mais composta por não nikkeis, que tiveram uma influência dos filmes japoneses em suas formações profissionais. O recorte não prejudica a pesquisa, mas deixa no ar questóes quanto a quem seriam os outros frequentadores não nikkeis? E de que maneira interagiam com o bairro da Liberdade?

Ao final, o livro relata o fechamento das salas nas décadas de 1970 e 1980, movimento de encerramento das atividades dos cinemas de rua que foi experimentado em todo o país. Ainda que espaços destinados exclusivamente aos filmes japoneses tenham acabado no dia-a-dia da cidade, as Mostras e Festivais de obras japonesas continuam a exercer fascínio em São Paulo. Com lotações das exibiçóes e presença dominante dos nikkeis, que muitas vezes ocupam todas as poltronas, não deixando espaço para os "curiosos". Alexandre Kishimoto, que tem descendência japonesa, coloca-se como um destes curiosos, relatando suas experiências na tentativa de participar das mostras e a frustração de não ter dado valor ao estudo do japonês quando seus pais o incentivaram, o que lhe fez falta durante a pesquisa.

Cinema japonês na Liberdade apresenta a relevância de nos voltarmos para o lazer para compreendermos as subjetividades, as identidades e as relaçóes sociais presentes entre 
os imigrantes japoneses no século XX em São Paulo. A recepção e o olhar sobre o tempo livre não costumam ser privilegiados nos estudos antropológicos sobre os "estrangeiros permanentes". O livro, ao argumentar nesse sentido, nos ajuda a compreender as relaçôes sociais, os costumes e os rituais que são formados a partir das relações que os imigrantes e seus descendentes estabeleciam com os espaços dos cinemas e com os filmes. Compreendemos também, de que maneiras as vivências em relação à cidade de São Paulo e ao Estado nacional foram sentidas por esses imigrantes e seus descendentes, ao mesmo tempo em que aspectos relativos às práticas culturais e afetividades relacionadas a uma origem japonesa se tornaram evidentes. Ao rememorar tais experiências vividas nas salas de cinema, o autor traz novas questóes para pensarmos antropologicamente sobre os significados das identidades quando observamos imigrantes e seu percurso geracional. Ao mesmo tempo, o trabalho instiga outros pesquisadores a pensar o "tempo livre" como momentos fundamentais para compreendermos as teias de significados tecidas nos contextos das vidas nas cidades ${ }^{2}$.

\section{Notas}

1 TURner, Victor W.; e Bruner, Edward M. (eds.). Anthropology of Experience. Urbana e Chicago, 1986. Traduzido para o português Herbert Rodrigues. Cadernos de Campo n.13: 177-185, 2005.

2 Agradeço às revisoras Eloísa Martín, Ana Carolina Miranda Accorsi, Raquel Dias Teixeira por suas leituras críticas sobre esta resenha. 